\title{
The association between use of online social networks sites and perceived social isolation among individuals in the second half of life: results based on a nationally representative sample in Germany
}

\author{
André Hajek *iD and Hans-Helmut König
}

\begin{abstract}
Background: To date, little is known about the association between the use of online social network sites and social isolation among individuals in the second half of life. Therefore, the aim of the present study was to examine this association among older adults.

Methods: Cross-sectional data was drawn from a nationally representative sample of non-institutionalized individuals aged 40 and above $(n=7837)$ in Germany (German Ageing Survey). Online social network use was assessed using the frequency of social network use (e.g., Facebook) in the preceding 12 months (daily; several times a week; once a week; 1-3 times a month; less often; never). Perceived social isolation was measured using an established scale created by Bude and Lantermann.

Results: Adjusting for covariates, linear regressions revealed that daily online social network users reported lower social isolation scores compared with those with less frequent or no social media use.

Conclusions: Data suggest that daily users of online social networks aged 40 and over tend to feel less socially isolated than less frequent users or non-users. Future research should concentrate on identifying the direction of this association. Moreover, the reasons underlying this finding should be examined.
\end{abstract}

Keywords: Social isolation, Social media use, Social exclusion, Germany

\section{Background}

Since the early 2000s, online social network sites (e.g., Facebook) have become increasingly popular throughout the world. This is particularly true among young adolescents and young adults. However, use of social network sites is also increasing among middle aged and older adults. As a number of those aged 40 years and older are already familiar with the internet and online social networks, it is likely that the proportion of individuals in old age using social networks will increase in the coming decades.

\footnotetext{
* Correspondence: a.hajek@uke.de

Department of Health Economics and Health Services Research, Hamburg Center for Health Economics, University Medical Center Hamburg-Eppendorf, Martinistr. 52, 20246 Hamburg, Germany
}

It has recently been demonstrated in a study of adults in the U. S. aged 19 to 32 years, that users of social media (e.g., Facebook) report higher perceived social isolation (used interchangeably: social exclusion) [1]. Social isolation is a feeling that one does not belong to the society. A positive association between the use of social network sites and loneliness (the perceived discrepancy between actual and desired social relationships) has also been shown among younger adults in different countries $[2,3]$. It is worth noting that while loneliness is related to social isolation, these are two distinct constructs [4] and they differ in their correlates [5].

To date, little is known about the association between the use of online social networks and social isolation among individuals in the second half of life. Previous

(c) The Author(s). 2019 Open Access This article is distributed under the terms of the Creative Commons Attribution 4.0 International License (http://creativecommons.org/licenses/by/4.0/), which permits unrestricted use, distribution, and reproduction in any medium, provided you give appropriate credit to the original author(s) and the source, provide a link to the Creative Commons license, and indicate if changes were made. The Creative Commons Public Domain Dedication waiver (http://creativecommons.org/publicdomain/zero/1.0/) applies to the data made available in this article, unless otherwise stated. 
studies focusing on older adults were interested in the relationship between social network sites and loneliness. For example, a recent study conducted by Aarts and colleagues on community-dwelling older adults $\geq 60$ years in the Netherlands $(n=626)$ showed that the use of online social network sites was neither related to loneliness in general, nor was it related to emotional and social loneliness [6]. In contrast, Leist concluded in a review that social media can reduce loneliness among older adults [7]. She stated that online communities are "places where people can get together and engage in social contact, e.g. overcome loneliness at nighttime" [7].

In order to close the gap in knowledge, the purpose of this study was to examine the link between the use of online social networks such as Facebook and social isolation among individuals aged 40 and over in Germany, using a nationally representative sample. Understanding this association is important due to the well-established association between social isolation, and morbidity as well as mortality [8].

Frequent users of social network sites may replace real life social interactions with these sites. Moreover, the frequent use of these sites may lead users to perceive that others have more, or better quality, social relationships than themselves, due to the unrealistic portrayals of reality on social network sites [1]. On the other hand, individuals who perceive themselves as socially isolated may feel less isolated when using social network sites, as these sites may facilitate relationship building by enhancing social ties $[9,10]$.

\section{Methods}

\section{Sample}

Data was drawn from the German Ageing Survey (German language: "Deutscher Alterssurvey", DEAS), a longitudinal cohort-based survey of non-institutionalized individuals $\geq 40$ years in Germany. Data collection took place in 1996 (first wave), 2002 (second wave), 2008 (third wave), 2011 (fourth wave), and 2014 (fifth wave). Both, cross-sectional and panel samples were included in the follow-up waves (with the exception of 2011, which was a pure panel survey). The response rate in 2014 was approximately $61 \%$ and $25 \%$ for the panel and the cross-sectional sample, respectively. This response rate is comparable to other large survey studies conducted in Germany [11], and similarly reflects the trend of decreasing rates in participation in surveys in Germany. It is worth noting that intense efforts were made to mitigate this trend in the DEAS study.

In this study, only data from the fifth wave was used, as both variables of interest (use of social networks in the internet and social isolation) were not assessed in previous waves. Further details with regard to the DEAS study can be found elsewhere [12].

\section{Dependent variables}

A scale created by Bude and Lantermann [13] was used to assess social isolation. This scale consists of four items, namely "I feel excluded from society", "I am worried to be left behind", "I feel that I am left out" and "I feel like I do not really belong to society". Respondents are asked to rate the strength of their agreement with the item from 1 to $4(1=$ "strongly agree" to $4=$ "strongly disagree"). All items were recoded. The score comprises the mean of at least 2 of the items, with higher values corresponding to higher social isolation. Consequently, it was considered as continuous variable. This is in line with previous research [14]. In this study, Cronbach's alpha was .88 .

Associations between social isolation and low education, as well as poverty, were demonstrated using this social isolation scale [15]. Moreover, an association between social isolation and use of preventive cancer screenings was identified using this social isolation scale [16].

\section{Independent variables}

Social network use was measured using the frequency of social network use (for example, popular social networks among older adults in Germany such as Facebook, StayFriends or feierabend.de) in the past 12 months ('daily'; 'several times a week'; 'once a week'; '1-3 times a month'; 'less often'; 'never').

Age, marital status (married, living together with spouse; other (widowed; divorced; single; married, living separated from spouse)), employment status (employed; retired; other (not employed)), equivalent monthly net income (OECD scale) were adjusted for in the regression analysis. Moreover, lifestyle factors were adjusted for, including the frequency of alcohol consumption, physical activity (in both cases: 'never', 'rarer than once a month', 'one to three times a month, 'once a week', 'several times a week', and 'daily') and smoking habits (non-smoker; former smoker; casual smoker; daily smoker). Self-rated health (ranging from $1=$ very good to $5=$ very bad) and the number of physical illnesses (hearing problems, ear problems; vision impairment, eye problems; bladder problems; liver or kidney problems; gall bladder; diabetes; cancer; stomach and intestinal problems; respiratory problems, asthma, shortness of breath; joint, bone, spinal or back problems; bad circulation; cardiac and circulatory disorders) were also included as potential confounders in the regression analysis.

In a sensitivity analysis, the robustness of the results was tested by adding depression (Center for Epidemiological Studies Depression Scale, CES-D $\geq 18$ [17]) and physical functioning (subscale 'physical functioning' of the SF-36 which ranges from 0 (worst) to 100 (best)) to our main model [18]. They were only used in the sensitivity analysis as the direction of the relationship 
between these variables and social isolation is both unclear and debated (reverse causality).

The main independent variable was replaced with another (broader) explanatory variable in a further analysis. This was carried out to determine whether the association between the use of social network sites and social isolation depends on the measure used to quantify the independent variable. Individuals with access to the internet were asked how often they use the internet for "contact with friends and relatives (e.g. e-mail, Facebook, chat, video calls)" ('daily'; 'several times a week'; 'once a week'; '1-3 times a month'; 'less often'; 'never').

Further tests were carried out to determine whether the association between the use of social network sites and social isolation was moderated by educational level.

\section{Statistical analysis}

First, sample characteristics were calculated (stratified by the use of social network sites). Second, multiple linear regressions were performed to examine the association between the use of social network sites and social isolation. Statistical significance was set set at $p<0.05$. Stata 15.0 (Stata Corp, College Station, TX, USA) was used to conduct statistical analysis. Regression analysis were run for the total sample and stratified by sex.

\section{Results}

\section{Description of the sample}

Sample characteristics, stratified by the use of social network sites, can be found in Table 1 (row percentages included). While daily users were on average 61.0 $( \pm 10.3)$ years old, non-users were $72.0( \pm 9.4)$ years old. Less than one out of two of daily users were retired, however approximately four out of five among the non-users were retired. In addition, daily users reported on average $2.3( \pm 1.7)$ physical illnesses, whereas non-users reported on average $3.2( \pm 2.0)$ physical illnesses. The mean physical functioning among daily users was 86.8 $( \pm 18.9)$, whereas mean physical functioning was 72.1 $( \pm 26.8)$ among non-users. Moreover, whilst $4.6 \%$ (139 out of 3002) of the daily users had depression, $8.0 \%$ of the non-users (189 out of 2363) had depression. The average social isolation scores among daily users and non-users were $1.5( \pm 0.5)$ and $1.7( \pm 0.7)$ respectively.

\section{Regression analysis}

In an adjusted analysis, the association between the use of online social network sites and social isolation was investigated (first column: total sample; second column: men; third column: women; Table 2).

Compared to daily users, less frequent users (e.g., several times a week (total sample): $\beta=.05, p<.01$ ) and non-users reported statistically significant higher social isolation scores in the total sample and in men (except for the group "1 to 3 times a month"). In women, the "less often" $(\beta=.09, p<.05)$ and "never" $(\beta=.07, p<.05)$ groups reported statistically significant higher social isolation scores compared to daily users. However, it is worth noting that gender differences (sex $\mathrm{x}$ use of social network sites) were not significant, with the exception of the interaction term "never" $\mathrm{x} \operatorname{sex}(\beta=-.08, p=.02)$.

As for the covariates (first column), social isolation was consistently positively associated with not being married, living together with spouse, being unemployed, lower income, lower age, poorer self-rated health as well as more physical illnesses in the total sample and in both sexes. Please see Table 2 for further details.

In a sensitivity analysis (see Additional file 1), the main model was extended by adding depression and physical functioning as covariates. In terms of effect size and significance, the association between the use of social network sites and social isolation remained almost the same in the total sample and in both sexes.

In a second sensitivity analysis, it was tested whether educational level moderates the association of interest (by including interaction terms educational level $\mathrm{x}$ use of social network sites). None of the interaction terms achieved statistical significance (see Additional file 2).

A third sensitivity analysis was conducted, where the main independent variable was replaced with the variable 'frequency of internet use for contact with friends and relatives (e.g. e-mail, Facebook, chat, video calling)'. The results were similar to those obtained in the prior regression analyses. Compared to daily users, less frequent users and non-users reported statistically significant higher social isolation scores (see Additional file 3).

\section{Discussion}

Drawing on a nationally representative sample of noninstitutionalized adults $\geq 40$ years, the objective of this study was to examine the association between the use of online social network sites and social isolation. Interestingly, non-users of social networks site were markedly older, more functionally impaired and had a higher number of physical illnesses compared to (daily) users in our study. Multiple linear regressions revealed that compared to daily users, less frequent users and non-users reported statistically significant higher social isolation scores.

To date, there is equivocal evidence concerning the association between the use of social networks sites and social isolation. The variance in results outlined in the introduction section can mainly be explained by differences in measuring the independent variable of interest (use of online social network sites), differences in the outcome measure (loneliness vs. social isolation) and large differences in the sample composition (e.g., student samples vs. community-dwelling older adults). Moreover, 


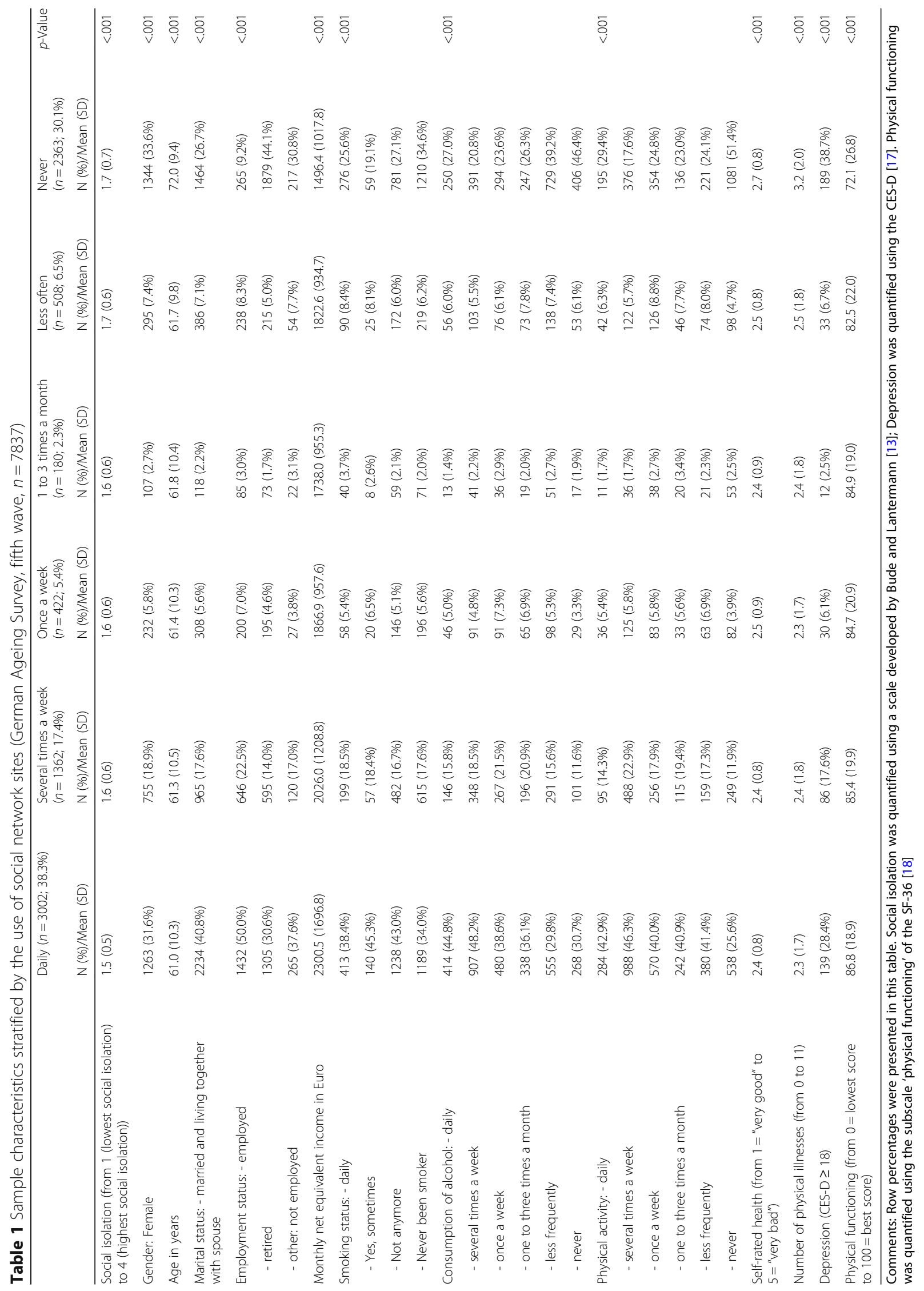


Table 2 Determinants of social isolation. Results of multiple linear regression analysis (German Ageing Survey, fifth wave)

\begin{tabular}{|c|c|c|c|}
\hline \multirow[t]{2}{*}{ Independent variables } & (1) & (2) & (3) \\
\hline & Total sample & Men & Women \\
\hline \multirow{2}{*}{$\begin{array}{l}\text { Use of social network } \\
\text { sites: - Several times a } \\
\text { week (Ref.: daily) }\end{array}$} & $0.05^{* *}$ & $0.06^{*}$ & 0.04 \\
\hline & $(0.02)$ & $(0.03)$ & $(0.03)$ \\
\hline \multirow[t]{2}{*}{ - Once a week } & $0.07^{*}$ & $0.12^{* *}$ & 0.04 \\
\hline & $(0.03)$ & $(0.04)$ & $(0.04)$ \\
\hline \multirow[t]{2}{*}{ - 1 to 3 times a month } & 0.05 & 0.10 & 0.02 \\
\hline & $(0.05)$ & $(0.08)$ & $(0.06)$ \\
\hline \multirow[t]{2}{*}{ - Less often } & $0.10^{* * *}$ & $0.09^{*}$ & $0.09^{*}$ \\
\hline & $(0.03)$ & $(0.04)$ & $(0.04)$ \\
\hline \multirow[t]{2}{*}{ - Never } & $0.10^{* * *}$ & $0.12^{* * *}$ & $0.07^{*}$ \\
\hline & $(0.02)$ & $(0.03)$ & $(0.03)$ \\
\hline \multirow[t]{2}{*}{ Age } & $-0.01^{* * *}$ & $-0.01^{* * *}$ & $-0.01^{* * *}$ \\
\hline & $(0.00)$ & $(0.00)$ & $(0.00)$ \\
\hline \multirow{2}{*}{$\begin{array}{l}\text { Marital status: Other } \\
\text { (divorced, widowed, } \\
\text { single, married, living } \\
\text { separated from spouse) } \\
\text { (Ref.: married and living } \\
\text { together with spouse) }\end{array}$} & $0.08^{* * *}$ & $0.11^{* * *}$ & $0.05^{*}$ \\
\hline & $(0.02)$ & $(0.02)$ & $(0.02)$ \\
\hline \multirow{2}{*}{$\begin{array}{l}\text { Employment status: - } \\
\text { Retired (Ref.: employed) }\end{array}$} & $0.08^{* * *}$ & $0.10^{* *}$ & $0.06+$ \\
\hline & $(0.02)$ & $(0.03)$ & $(0.03)$ \\
\hline \multirow[t]{2}{*}{ - Other: not employed } & $0.17^{* * *}$ & $0.19^{* * *}$ & $0.15^{* * *}$ \\
\hline & $(0.03)$ & $(0.05)$ & $(0.04)$ \\
\hline \multirow{2}{*}{$\begin{array}{l}\text { Monthly net equivalent } \\
\text { income in } 1000 \text { Euro }\end{array}$} & $-0.04^{* * *}$ & $-0.04^{* * *}$ & $-0.05^{* * *}$ \\
\hline & $(0.01)$ & $(0.01)$ & $(0.01)$ \\
\hline \multirow{2}{*}{$\begin{array}{l}\text { Smoking status: - Yes, } \\
\text { sometimes (Ref.: Daily) }\end{array}$} & $-0.07^{*}$ & -0.02 & $-0.13^{*}$ \\
\hline & $(0.03)$ & $(0.05)$ & $(0.05)$ \\
\hline \multirow[t]{2}{*}{ - Not anymore } & -0.01 & -0.02 & 0.01 \\
\hline & $(0.02)$ & $(0.03)$ & $(0.03)$ \\
\hline \multirow[t]{2}{*}{ - Never been smoker } & -0.03 & -0.04 & 0.00 \\
\hline & $(0.02)$ & $(0.03)$ & $(0.03)$ \\
\hline \multirow{2}{*}{$\begin{array}{l}\text { Consumption of alcohol: - } \\
\text { Several times a week } \\
\text { (Ref.: Daily) }\end{array}$} & 0.00 & 0.01 & -0.03 \\
\hline & $(0.02)$ & $(0.03)$ & $(0.04)$ \\
\hline \multirow[t]{2}{*}{ - Once a week } & 0.01 & $0.06^{*}$ & $-0.09^{*}$ \\
\hline & $(0.02)$ & $(0.03)$ & $(0.04)$ \\
\hline \multirow[t]{2}{*}{ - 1 to 3 times a month } & $0.04+$ & $0.08^{*}$ & -0.03 \\
\hline & $(0.03)$ & $(0.04)$ & $(0.04)$ \\
\hline \multirow[t]{2}{*}{ - Less often } & $0.06^{*}$ & $0.09^{*}$ & 0.00 \\
\hline & $(0.02)$ & $(0.03)$ & $(0.04)$ \\
\hline \multirow[t]{2}{*}{ - Never } & $0.11^{* * *}$ & $0.15^{* * *}$ & 0.04 \\
\hline & $(0.03)$ & $(0.04)$ & $(0.05)$ \\
\hline \multirow{2}{*}{$\begin{array}{l}\text { Physical activity: - Several } \\
\text { times a week (Ref.: Daily) }\end{array}$} & -0.03 & -0.04 & -0.03 \\
\hline & $(0.02)$ & $(0.04)$ & $(0.03)$ \\
\hline \multirow[t]{2}{*}{ - Once a week } & 0.00 & -0.02 & 0.02 \\
\hline & $(0.03)$ & $(0.04)$ & $(0.04)$ \\
\hline
\end{tabular}

Table 2 Determinants of social isolation. Results of multiple linear regression analysis (German Ageing Survey, fifth wave) (Continued)

\begin{tabular}{llll}
\hline Independent variables & $(1)$ & $(2)$ & $(3)$ \\
& Total sample & Men & Women \\
\hline - 1 to 3 times a month & 0.03 & -0.01 & 0.07 \\
& $(0.03)$ & $(0.04)$ & $(0.05)$ \\
- Less often & -0.01 & -0.04 & 0.02 \\
& $(0.03)$ & $(0.04)$ & $(0.04)$ \\
- Never & 0.02 & 0.00 & 0.03 \\
& $(0.03)$ & $(0.04)$ & $(0.04)$ \\
Self-rated health (from & $0.10^{* * *}$ & $0.11^{* * *}$ & $0.09^{* * *}$ \\
1= "very good" to & $(0.01)$ & $(0.01)$ & $(0.01)$ \\
$5=$ "very bad") & $0.05^{* * *}$ & $0.04^{* * *}$ & $0.05^{* * *}$ \\
Number of physical & $(0.00)$ & $(0.01)$ & $(0.01)$ \\
illnesses (from 0 to 11) & $1.60^{* * *}$ & $1.52^{* * *}$ & $1.71^{* * *}$ \\
Constant & $(0.07)$ & $(0.10)$ & $(0.10)$ \\
& 7141 & 3549 & 3592 \\
Observations & 0.12 & 0.14 & 0.10 \\
\hline R &
\end{tabular}

Comments: Beta-Coefficients are reported; robust standard errors in parentheses. ${ }^{* *} p<0.001,{ }^{* *} p<0.01,{ }^{*} p<0.05,+p<0.10$. Social isolation was quantified using a scale developed by Bude and Lantermann [13]

we assume that age is associated with the motivation to use online social network sites, which may influence the strength of association between their use and social isolation.

How can our findings be explained? Intuitively, one might assume that time spent on social networks replaces real life social experiences, which are associated with actual decreases in social isolation [1]. Moreover, use of social network sites may facilitate comparisons of oneself to idealized portrayals of others, or may highlight instances where one is not invited to an event and/or social gathering. Such instances may elicit feelings of envy and may result in social isolation [1]. Realistic evaluation of images and events viewed via such sites may lead to the opposite response by the user. That is, the user may conclude that he or she is better off socially than others are, leading to decreased social isolation. This possibility could explain our results. Another way to explain our findings might be that daily users in the second half of life might compare with less frequent or non-users. Daily users might also conclude that they are better off than the latter groups because they are still able to participate in social network sites which in turn might reflect a better perceived health status compared to the latter groups $[19,20]$. This might result in decreased social isolation. It appears plausible that daily users have a better health status compared to non-users. In Table 1 , it was, for example, shown that daily users reported better health (in terms of self-rated health, number of physical illnesses, depression or physical functioning). 
This study has several strengths. To our knowledge, this is the first study investigating the relation between the use of social network sites and social isolation based on a nationally representative sample of community-dwelling individuals in the second half of life in Germany. Social isolation was quantified using an established scale developed by Bude and Lantermann. It was adjusted for various potential confounders, including socioeconomic, lifestyle and health-related factors. The frequency of social network use in the past 12 months was used to quantify the social network use. The robustness of our findings was checked by replacing this variable with a broader variable covering the frequency of internet use for contact with friends and relatives in general. However, further research that assesses the time spent using social network sites is required. As this is a cross-sectional study, changes within individuals over time could not be examined. Further research is needed to clarify the direction of this relationship. In addition, a reasonably small sample selection bias has been reported in the DEAS study [12].

\section{Conclusion}

Unexpectedly, data suggest that daily users of online social network sites aged 40 and over tend to feel less socially isolated than less frequent users or non-users. Future research should concentrate on identifying the direction of this association. Moreover, the reasons underlying these findings should be examined. The association could differ by personality type, cultural settings, and/or geographical location. Furthermore, the type of social media use (e.g., distinguishing between passive consumers and active users) [9] should be investigated in depth

\section{Additional files}

Additional file 1: Determinants of social isolation. Results of multiple linear regression analysis (German Ageing Survey, fifth wave) (with additional control variables). (DOCX $16 \mathrm{~kb}$ )

Additional file 2: Determinants of social isolation. Results of multiple linear regression analysis (with interaction terms: use of social network sites $x$ education). (DOCX $16 \mathrm{~kb}$ )

Additional file 3: Determinants of social isolation. Results of multiple linear regression analysis (German Ageing Survey, fifth wave) (with another main independent variable). (DOCX $16 \mathrm{~kb}$ )

\section{Abbreviations}

CES-D: Center for Epidemiological Studies Depression Scale; DEAS: German Ageing Survey; OECD: Organization for Economic Co-Operation and Development

\section{Acknowledgements}

Not applicable.

\section{Availability of data and materials}

The data used in this study are third-party data. The anonymized data sets of the DEAS (1996, 2002, 2008, 2011, and 2014) are available for secondary analysis. The data has been made available to scientists at universities and research institutes exclusively for scientific purposes. The use of data is subject to written data protection agreements. Microdata of the German Ageing Survey (DEAS) is available free of charge to scientific researchers for nonprofitable purposes. The FDZ-DZA provides access and support to scholars interested in using DEAS for their research. However, for reasons of data protection, signing a data distribution contract is required before data can be obtained. Please see for further Information (data distribution contract): https://www.dza.de/en/fdz/access-to-data/formular-deas-en-english.html

\section{Authors' contributions}

AH, HHK: Design and concept of analyses, preparation of data, statistical analysis and interpretation of data, preparing of the manuscript. All authors critically reviewed the manuscript, provided significant editing of the article and approved the final manuscript.

\section{Ethics approval and consent to participate}

An ethical statement for this study was not required since the criteria for such a statement were not fulfilled (for instance, examination of patients, risk for the respondents, lack of information about the goals of the study, use of invasive methods).

Prior to the interview, written informed consent was given by all participants of the study.

\section{Consent for publication}

Not applicable.

\section{Competing interests}

The authors declare that they have no competing interests.

\section{Publisher's Note}

Springer Nature remains neutral with regard to jurisdictional claims in published maps and institutional affiliations.

Received: 3 May 2018 Accepted: 27 December 2018

Published online: 09 January 2019

\section{References}

1. Primack BA, Shensa A, Sidani JE, Whaite EO, Yi Lin L, Rosen D, Colditz JB, Radovic A, Miller E. Social media use and perceived social isolation among young adults in the US. Am J Prev Med. 2017;53(1):1-8.

2. Lemieux R, Lajoie $S$, Trainor NE. Affinity-seeking, social loneliness, and social avoidance among Facebook users. Psychol Rep. 2013:112(2):545-52.

3. Ye Y, Lin L. Examining relations between locus of control, loneliness, subjective well-being, and preference for online social interaction. Psychol Rep. 2015;116(1):164-75.

4. Victor CR, Scambler SJ, Bowling A, Bond J. The prevalence of, and risk factors for, loneliness in later life: a survey of older people in Great Britain. Ageing Soc. 2005;25(6):357-75.

5. Hajek A, König H-H. The association of falls with loneliness and social exclusion: evidence from the DEAS German ageing survey. BMC Geriatr. 2017;17(1):204.

6. Aarts $S$, Peek $S$, Wouters $E$. The relation between social network site usage and loneliness and mental health in community-dwelling older adults. Int J Geriatr Psychiatry. 2015;30(9):942-9.

7. Leist AK. Social media use of older adults: a mini-review. Gerontology. 2013; 59(4):378-84.

8. Pantell M, Rehkopf D, Jutte D, Syme SL, Balmes J, Adler N. Social isolation: a predictor of mortality comparable to traditional clinical risk factors. Am J Public Health. 2013;103(11):2056-62.

9. Ellison NB, Steinfield C, Lampe C. The benefits of Facebook "friends:" socia capital and college students' use of online social network sites. J Comput Mediat Commun. 2007;12(4):1143-68.

10. Steinfield C, Ellison NB, Lampe C. Social capital, self-esteem, and use of online social network sites: a longitudinal analysis. J Appl Dev Psychol. 2008. 29(6):434-45. 
11. Neller K. Kooperation und Verweigerung. Eine non-response-Studie [cooperation and refusal: a non-response study]. ZUMA Nachrichten. 2005; 29(57):9-36.

12. Klaus D, Engstler H. Daten und Methoden des Deutschen Alterssurveys. In: Mahne K, Wolff JK, Simonson J, Tesch-Römer C, editors. Altern im Wandel: Zwei Jahrzehnte Deutscher Alterssurvey (DEAS). Berlin; 2016. p. 25-42.

13. Bude H, Lantermann E-D. Soziale Exklusion und Exklusionsempfinden. KZfSS. 2006:58(2):233-52.

14. Franke J, Simonson J. Social justice beliefs regarding old-age provisions in Germany: a latent profile analysis. Soc Justice Res. 2018:1-24.

15. Böger $A$, Wetzel $M$, Huxhold O. Allein unter vielen oder zusammen ausgeschlossen: Einsamkeit und wahrgenommene soziale Exklusion in der zweiten Lebenshälfte. In: Mahne K, Wolff JK, Simonson J, Tesch-Römer C, editors. Altern im Wandel: Springer; 2017. p. 273-85.

16. Hajek A, Bock JO, König $\mathrm{HH}$. The role of general psychosocial factors for the use of cancer screening - findings of a population-based observational study among older adults in Germany. Cancer Med. 2017;6(12):3025-39.

17. Radloff LS. The CES-D scale a self-report depression scale for research in the general population. Appl Psychol Meas. 1977;1 (3):385-401.

18. Ware JE Jr, Sherbourne CD. The MOS 36-item short-form health survey (SF36): I. conceptual framework and item selection. Med Care. 1992:473-83.

19. Hajek A, König HH. Negative health comparisons decrease affective and cognitive well-being in older adults. Evidence from a population-based longitudinal study in Germany. Front Psychol. 2016;7:999.

20. Hajek A, König HH. Self-efficacy moderates the relationship between health comparisons and social exclusion: results of the German ageing survey. Health Qual Life Outcomes. 2017;15(1):252.

Ready to submit your research? Choose BMC and benefit from:

- fast, convenient online submission

- thorough peer review by experienced researchers in your field

- rapid publication on acceptance

- support for research data, including large and complex data types

- gold Open Access which fosters wider collaboration and increased citations

- maximum visibility for your research: over $100 \mathrm{M}$ website views per year

At $\mathrm{BMC}$, research is always in progress.

Learn more biomedcentral.com/submissions 